\title{
COPING MECHANISMS OF SME IN RESPONSE TO 2011 FLOODS IN PATHUMTHANI, THAILAND
}

\author{
S. PATHAK ${ }^{1} \&$ M.M. AHMAD 2 \\ ${ }^{1}$ Disaster Preparedness, Mitigation and Management, Asian Institute of Technology, Thailand. \\ ${ }^{2}$ Associate Professor, Asian Institute of Technology, Thailand.
}

\begin{abstract}
Disaster recovery for SMEs are related to bouncing back after the disaster event and attaining resilience and self-dependency. This study focuses on the flood recovery coping mechanism adopted by the small and medium enterprises (SMEs) in Pathumthani province of Thailand post 2011 floods. Thailand is a middle income country prone to natural hazards with a major risk from the floods. The affected population includes all sectors of the society such as business. The SMEs contribute a major share in the GDP of Thailand and are have to be protected from the disastrous impacts of the re-occurring floods. This paper analyses the capacities adopted by the manufacturing SMEs to recover from the floods in the Pathumthani province in Thailand. It is based on extensive literature review synthesis and a methodological approach to ascertain the impacts and coping mechanisms of flood disaster to vulnerable SMEs in the Pathumthani province, Thailand.

Keywords: coping mechanisms, disaster, disaster recovery, disaster risk reduction, floods impact, small and medium enterprises (SMEs).
\end{abstract}

\section{INTRODUCTION}

The 2011 floods event, which is also termed as 'Great Floods', is chosen to ascertain the maximum impacts that were faced by the small and medium enterprises (SMEs) in the recent times. Thailand is a developing economy and SMEs contribute significantly to the Thai growing economy by generating employment and adding to the GDP and alleviate poverty $[1,2]$. There was a tremendous growth in the SMEs during the years 1985 to 1995 in Thailand [3]; however, a declining trend is observed after this period [4]. Still almost $70 \%$ of the total employment in Thailand is generated through SMEs [1].

The study focuses on the recovery strategies adopted by the SMEs in the Pathumthani province of Thailand to cope up with the reoccurring floods. The flood event of 2011 is taken as the sample year of impact, which affected majority of the SMEs in Thailand. The paper analyses the various factors that contribute to recovery of these SMEs from the floods and how could they be managed in a way to achieve faster recovery from future flood events.

\section{FLOODS IN THAILAND}

The Floods affect almost all walks of life as a slow receding disaster. Flood impacts directly on the human lives, infrastructure, plant and machinery, transportation and warehouse storage capacities [5]. The floods impact indirectly on the social and psychological set up of any 
community, as production is hurdled, negative impacts on market values of property and stock market [6].

The coping mechanism of the SMEs from the floods involves various factors that work together to attain resilience and sustainability from catastrophic flood events. These factors include SME's size, type, location [7], disaster risk perception and management techniques adopted [4, 8], financial resilience [4], flood risk mapping, community support, research and development on SMEs [1], governmental aid on both local as well as national level and aid from various non-governmental organisations. SMEs are severely affected in the absence of disaster risk reduction, business risk assessment and business continuity planning [9, 10]. The limitation of the SMEs in terms of location, small workforce and reach to limited market enhances the disaster risk $[11,12]$. The study found out that apart from these factors absence of insurance is one of the major factors affected the recovery time period for the SMEs $[9,13,14]$.

\section{DISASTER RECOVERY IN THAI SMES}

Disaster recovery studies in the past have overlooked the SMEs affected by disasters $[15,16]$ as most of them are focused on the household or community level, government bodies and departments dealing with emergency services $[17,18]$. Few studies have been found on disasters and their impact on SMEs [19-21]. There is a dire need to study the SMEs as large firms have adequate resources and access to finances that lead to faster recovery than the SMEs [19].

In Thailand during the floods of 2011, the SMEs were heavily impacted by floods and recovery period extended from few hours to over a year depending upon the size, financial resources and managerial decision making. The overall sample size of 200 SMEs revealed (refer Table 1) that flood preventive measures adopted by the SMEs prior to the floods resulted in faster recovery $(2 \%)$ in comparison to the others especially two SMEs which have been unable to commence the business till date $(1 \%)$. Such huge time difference in the recovery period influence the overall industrial output due to linkages of supply chain from the SMEs, which provide the raw materials.

\section{THAI SMES}

SMEs in Thailand have been defined on the basis of capital invested or number of employees. SMEs in Thailand are defined as those enterprises, which employ less than 200 employees,

Table 1: Recovery time taken by sample SMEs in Pathumthani district.

\begin{tabular}{lcc}
\hline $\begin{array}{l}\text { Recovery Time period } \\
\text { (in month/s) }\end{array}$ & $\begin{array}{c}\text { Frequency } \\
\text { (Number of SMEs) }\end{array}$ & Percent \\
\hline 0 & 4 & 2.0 \\
$0.1-1$ & 41 & 20.5 \\
$1.1-3$ & 93 & 46.5 \\
$3.1-6$ & 52 & 26.0 \\
$6.1-12$ & 8 & 4.0 \\
Never & 2 & 1.0 \\
Total & 200 & 100.0 \\
\hline
\end{tabular}

Source: Field Survey. 
having investment capital of less than 100 million baht, and fixed assets of less than 100 million baht $[22,23]$. SMEs are termed as 'boresat' in the native Thai language and contribute to the second largest employment opportunity after agriculture [24].

The SMEs in Thailand are categorised on the basis of three primary sectors including production/manufacturing, trading and services. The major portion of the SMEs are in the manufacturing sector and contributed to the selection of these enterprises to be studied as the flood impact on these firms affects further supply chain and export/import of the Thai economy as a whole. These small business enterprises are more vulnerable towards the adverse impacts of floods [5]. The study is focused to prevent the SMEs damage from future flood events.

\section{METHODOLOGY}

The study was carried out in seven districts of the Pathumthani province of Thailand. The province has a total of 401 SMEs [23] out of which a sample size of 200 companies [25] was selected. The study focused on the coping mechanisms adopted by the affected SMEs in the study area in order to recover from the devastating floods of 2011.

The methodology involved qualitative and quantitative methods by the usage of survey questionnaires, key informant interviews and focused group discussions along with secondary data gathered from various concerning institutions, bodies and previous literatures on flood recovery for SMEs in Thailand. The data was collected in three distinct phases. The first visit provided a detailed information of the study area which assisted the second phase in collection of survey data according to the 2011 flood affected SMEs. The survey questionnaire involved multiple choice and open-ended questions to gather information related to SME's profile, management, and impacts incurred from the 2011 floods, disaster risk perception and adopted coping mechanisms. The survey questionnaire respondents included the hired managers and owners/managers who are managing a company in the Pathumthani district.

The respondents consisted of $70.5 \%$ males and $29.5 \%$ females. The respondents were among the age group of 21-30 years (20\%), 31-40 years (35.5\%) and beyond $40(44.5 \%)$ and the education level comprised of graduates $(66 \%)$, post graduates $(11 \%)$ and below graduation level $(23 \%)$.

\section{FINDINGS AND DISCUSSIONS}

The study finds out the severe impacts from floods had been borne by the SMEs during the floods of 2011.The damages included financial, social as well as psychological losses. The government aid and policies lack the force for faster recovery of these enterprises. The non-governmental sector is almost negligible in terms of assistance during the floods for the SMEs. The major recovery was brought through the financial assistance from the owners own equity or through the profits of future business, which pushed the recovery process for over a period of months. The growth is hampered as recovery time period is elongated due to lack of supporting mechanism from various governmental or non-governmental bodies. The recent political turmoil and droughts (2015) have added to the already affected recovery, created hurdles in the growth and development of the SMEs.

\subsection{Socio-economic impact}

The production was on standstill for a period of 2 months (mid-October to mid-December), however, after the floods receded, it was hard for the SMEs to jump start the production due 


\section{Flood Risk Management and Response}

to non-existence of adequate finances. It took around five months (March 2012) on an average for the SMEs to restart the production of the enterprise. However, two SMEs were unable to recover from the 2011 floods in the study area and finally winded up their business activity leading to loss of employment for 67 employees.

The financial losses were enormous as almost $40 \%$ of the total sample size had to bear an economic loss of more than 1 million baht. These economic losses included production days, sales, stock and other miscellaneous expenses to claw back to the normalcy of the business activities. However, the costs of repair and purchasing of new machineries and equipment is not included. The total financial impact is almost double when the total expenses incurred are calculated.

Thailand being an upper middle income country, largely depends upon the SMEs for future development and sustainable growth in the economy. The SMEs in the developing countries have general tendency to operate in hazard prone and vulnerable locations, lack of human and financial resources, limited institutional capacity and inadequate futuristic planning in terms of disaster risk [13]. The study found the limitations of financial resources for SMEs in the study area along with misconceptions regarding flood risk and importance of mitigation tools such as flood insurance and medical insurance policies for the workforce.

Almost $85 \%$ of the sample size in the study depicted lack of financial resources and sustainability through preparedness and mitigation strategies to cope from a natural hazard. SMEs lack planning for business continuity and risk transfer mechanism during an unforeseen natural calamity $[5,11,12,13]$. The flood disaster recovery has a positive association with the business risk perception and the financial resources at the management's disposal during a disaster event. Therefore, the SMEs should try to identify adequate financial security and sustainable mechanisms to recover faster from the recurring Thai floods.

\subsection{Flood risk}

Flood risk is a recurring risk in the Pathumthani province as it lies in the catchment area of the Chao Phraya River, the largest river running through the northern and central provinces. The respondents were vulnerable to the flood risk and had adopted various mitigation measures using their indigenous knowledge. However, they lack the motivation and interest for adopting preparedness and mitigation tools such as structural and non-structural measures such as insurance and flood recovery planning.

Risk perception is a predominant factor in the formulation of flood disaster risk reduction policies and planning [26]. The risk perception would formulate the managerial decision making in SMEs during disaster scenarios. This study finds out that the SMEs have been reluctant in acknowledging the flood risks. We found that they have a laid back and carefree attitude towards future flood risk. A severely affected respondent from a leading noodle company Mr. Nattaporn Noree adds

'There is no flood risk in our area. We did get flooded in 2011 but I think the government will take care of it in case it happens in future. Similarly, we don't need insurance also, we will cross the bridge when we reach there!'

Such attitudes toward the flood risk need to be revisited both at governmental and individual level. The flood disaster risk is prevalent in the area, therefore, the risk prevails but in 
terms of perception, the SMEs are safe from flood risk. The negligence of the risk further reduces the adoption of coping mechanisms while enhancing vulnerability.

\subsection{Government aid and assistance}

The Thai government has been taking various steps at the national as well as local levels to assist the population from the impacts of the floods, however in 2011, the management of floods by the government was heavily criticized. Around $88 \%$ of the respondents were not satisfied with the government policies regarding the flood and water management during 2011 floods. SMEs stood alone during the floods and efforts were focused on relief rather than commencement of the recovery process. It was found that there was an acute lack of SME database, which in turn affected the recovery process and policy formulation [27]. With the recent political instability in the country, disaster recovery initiatives have taken a back seat both at SME and government level.

The government was also heavily criticized for untimely and inaccurate early flood warning (refer Table 2. In spite of various local level bodies working on $24 * 7$ basis, the SMEs were unable to receive flood early warning from the government. The major source was through social media and word of mouth information dissemination during the floods. We found that only $72 \%$ of SMEs received the early warning, out of which only $38 \%$ had more than a day notice. This was a crucial factor as the SMEs were unable to cope and prepare for the coming flood waters.

The government has a crucial role in disaster recovery. The governing of several factors such as disaster management, aid and assistance programs forms the foundation of faster disaster recovery and enables the economy to bounce back to normalcy. We found out that there is lack of emphasis from the government on Pre-disaster mitigation, inclusion of NGOs, disaster management and recovery planning and adopting insurance as a necessary requirement to curtail the flood losses and provide sustainability to the business unit in itself for speeding up their recovery process. A key informant from an NGO working for SMEs in the province added

"The government should include us in the disaster management infrastructure. We have the human resources and volunteers who are willing to assist in flood times. A proper pre-disaster management planning could enable the SMEs to reduce losses and cope up faster from floods as was the case in 2011."

Table 2: Flood early-warning time taken to disseminate warning to SMEs.

\begin{tabular}{lcc}
\hline Warning time & Frequency & Percent \\
\hline No warning & 56 & 28 \\
Less than $1 \mathrm{~h}$ & 21 & 10.5 \\
$1-6 \mathrm{~h}$ & 26 & 13 \\
$7-12 \mathrm{~h}$ & 9 & 4.5 \\
$13-24 \mathrm{~h}$ & 12 & 6 \\
$+24 \mathrm{~h}$ & 76 & 38 \\
Total & 200 & 100
\end{tabular}

Source: Field Survey. 


\subsection{Coping mechanisms}

The coping mechanisms adopted by the SMEs during the 2011 floods depicts a lack of adequate risk assessment, planning and managerial approach. The subsequent results were huge economic damages and long recovery time periods (refer Table 1). The following is the SWOT analysis on the basis of data collected from SMEs and other stakeholders including government and non-government organizations.

The SWOT analysis of the existing coping mechanisms involves:

Strengths: The current coping mechanisms are related to various aids and assistance provided by the Thai government. The political structure provides for basic disaster response and relief to the affected communities. The local level government provides immediate assistance in terms of food and other basic amenities. However, there is a lack of focused assistance towards SMEs and business community.

An example from a SME manager Mr. Nattapol who quoted

'The government was very prompt in providing food, water and basic amenities. The staff also helped in recovering from losses and assisted even during flood time. The main problem arose once the company was to restart its daily business.'

Weaknesses: The major setback was in the managerial decision making both at SME and governmental level. The tremendous impact of 2011 floods was largely due to the misperception of the flood risk. The SMEs were not prepared and government lacked in providing early warning. The financial resources of SMEs were limited and the government focused on disaster relief and response as the scale of 2011 floods was enormous and beyond measures for the Thai government.

Opportunities: There were ample opportunities for the SMEs if they would have prepared for the uncertainties and perceive the flood risk prior to the 2011 floods. The existing opportunities involved tax rebates and other incentives given to the SMEs during the next three years subsequent to the 2011 floods. The business continuity planning and disaster risk management planning proved to be effective in the disaster scenario for some SME's that had prepared adequately.

In the words of SME owner and manager Mr. Tantripol Pornsiri

"We were not affected by the 2011 floods at all. The planning was in place and we carried out business activities from our Bangkok branch. The factory was secured with insurance, disaster management plans and measures such as boats, flood dykes around the premises and $24 * 7$ security guards on duty during the flood months."

Threats: The absence of participatory approach from all the stakeholders involved resulted in enhanced vulnerabilities and threats for the SMEs and eventually to the economy as a whole [28]. The perception of risk was a major threat towards sustaining the floods [29]. Pathumthani province is vulnerable to reoccurring floods. There is a dire need to reduce the vulnerabilities through effective flood early warning system and policy level implications and implementations. The effective use of information and available resources would assist in curtailing enormous impacts of floods among the SMEs.

The overall approach has been towards achieving faster flood disaster recovery for SMEs. The future success depends on the improvisations and additions of new and better coping mechanisms on national, local as well as SME level. 


\subsection{Disaster risk management \& disaster recovery}

Disaster risk management deals with the mechanisms involving reduction of vulnerabilities of the unforeseen disasters and provide sustainable and resilient development. In terms of the business sector, it is essential to perceive the risk in its actual state and provide for its adequate and effective disaster management planning and mitigation measures. The overall process of flood disaster management and rapid recovery involves four distinct stages as described below.

Stage 1: Flood Risk Assessment - The first stage involves the able and effective managerial decision making, accurate risk perception to develop and frame the business continuity planning in accordance with the disaster risk reduction planning for future hazards. Through proper governmental policies and utilizing new technologies such as remotely sensed data [30], the flood risk assessment process would provide for a robust and holistic policy framework for coping from disasters such as floods.

Stage 2: Flood Risk Planning - Planning ahead of a hazard is a key to better managing the disaster event. The flood risk planning process involves undertaking every aspect of disaster, risk and ensuring faster recovery after the disaster event. It is essential to plan ahead to be resilient towards the future uncertainty [31]. The climate change impacts are to be included in the planning, as the effects are not uniform throughout an economy [32]. The planning must ensure reduced risk through tools including financial resources, risk transfer tools and sustainable progress of the enterprise.

Stage 3: Flood Disaster Management - The success of flood disaster risk management is dependent upon the accuracy of the flood risk assessment and planning [33]. The external factors such as political and government policies and assistance programs must be fully utilized by the flood risk management. Disasters might open new horizons for the enterprise to grow; however, the chances are reduced if proper risk management is absent.

Stage 4: Flood Recovery - The post flood recovery is of utmost importance due to the fact that SMEs provide for social and economic development. The faster the SMEs recover from the disaster event, the faster would be economic growth of the economy. The vulnerabilities are reduced with adequate implementation of the disaster recovery mechanisms. It is essential to provide for faster recovery to the SMEs as they act as a lifeline to the economy and contribute towards sustainable development.

\section{CONCLUSION}

The study has identified the loopholes in disaster management and recovery mechanism adopted among the SMEs during the 2011 flood in the affected areas of Pathumthani Province. The lack of government planning and policy implementation, non-utilization of adequate financial and managerial disaster recovery tools, such as insurance and business continuity planning are the major factors responsible for the longer recovery of SMEs after the natural disaster.

The existing coping mechanisms are unable to reduce the long recovery time. The disaster risk reduction and disaster recovery had to be involved at all levels of policy formulations. The government should focus on recovery as well as disaster preparedness among the SMEs that are crucial for the provincial growth and development, which in turn increases the national productivity and strengthen the economy.

We have found that with adequate flood preparedness and business continuity strategies adopted at SME and government levels the total recovery period after a flood event would be 
optimally reduced. A comprehensive disaster risk reduction and business continuity planning would enhance the sustainability of the SMEs in Pathumthani province from future flood hazards. The government could assist before the disaster strikes in terms of risk awareness campaigns, training exercises and propagating self-sustainability through insurance. The post disaster relief and recovery strategies involve restoration of critical facilities, tax subsidies and risk reduction workshops and follow up.

SME forms the major contributor to middle income countries economy. Thai SMEs need to be flood resilient in order to maintain their continuous contributions towards the Thai economy. There are several loopholes in the current system of SME in the Pathumthani and other provinces in Thailand. There is a dire need to further investigate the factors contributing towards SME vulnerability towards disasters. The joint efforts of all stakeholders involved would result in sustainable and resilient SMEs from any future disasters.

\section{REFERENCES}

[1] OSMEP, "Situation and Structural Indicators of SMEs in 2008 and 5-Year Changes," White Paper on SMEs 2008 and Trends 2009, 2008.

[2] Tannock, J., Krasachol, J. \& Ruangpermpool, S., The development of total quality management in Thai manufacturing SMEs: A case study approach. International Journal of Quality \& Reliability Management, 19(4), pp. 380-395, 2002. http://dx.doi.org/10.1108/02656710210421562

[3] Régnier, P., Small and Medium Enterprises in Distress: Thailand, the East Asian Crisis and Beyond, Hampshire: Gower, p. 181, 2000.

[4] Sleuwaegen, L. \& Goedhuys, M., Growth of firms in developing countries, evidence from Co`te d'Ivoire. Journal of Development Economics, 68, pp. 117-135, 2002. http://dx.doi.org/10.1016/S0304-3878(02)00008-1

[5] Alesch, D.J., Holly, J., Mittler, E. \& Nagy, R., Organizations at Risk: What Happens when Small Businesses and Not-for-Profits Encounter Natural Disasters. Public Entity Risk Institute, Fairfax, VA, 2001.

[6] Rose, A., A framework for analyzing the total economic impacts of terrorist attacks and natural disasters. Journal of Homeland Security and Emergency Management, 6(1), pp. 2009.

[7] Brush, C.G., Ceru, D.J. \& Blackburn, R., Pathways to entrepreneurial growth: The influence of management, marketing, and money. Business Horizons, 52, pp. 481-491, 2009. http://dx.doi.org/10.1016/j.bushor.2009.05.003

[8] Lind, P., Artist, The SME in a Global Context - Cultural Impact. [Art]. Gotland University, 2009.

[9] Zhang, Y., Lindell, M.K. \& Prater, C.S., Vulnerability of community businesses to environmental disasters. Disasters, 33, (1), pp. 38-57, 2009. http://dx.doi.org/10.1111/j.1467-7717.2008.01061.x

[10] Asgary, A. \& Sadeghi Naini, A., Modelling the adaptation of business continuity planning by businesses using neural networks. Intelligent Systems in Accounting, Finance and Management, 18, pp. 89-104, 2011. http://dx.doi.org/10.1002/isaf.326

[11] McClure, D.L., Disaster recovery for small businesses. Central U.S. Earthquake Consortium Journal, 7(1), p. 10, 2000.

[12] Webb, G., Tierney, K. \& Dahlhamer, J., Business and disasters: empirical patterns and unanswered questions. Natural Hazards Review, 1(2), pp. 83-90, 2000. 
http://dx.doi.org/10.1061/(ASCE)1527-6988(2000)1:2(83)

[13] Green, R., Miles, S., Gulacsik, G. \& Levy, J., Business recovery related to highfrequency natural hazard events. Quick Response Report, Natural Hazards Centre, 2008.

[14] Yoshida, K. \& Deyle, R., Determinants of small business hazard mitigation. Natural Hazards Review, 6(1), pp. 1-12, 2005. http://dx.doi.org/10.1061/(ASCE)1527-6988(2005)6:1(1)

[15] Quarantelli, E.L., Disaster crisis management: a summary of research findings. Journal of Management Studies, 25(4), pp. 373-385, 1988. http://dx.doi.org/10.1111/j.1467-6486.1988.tb00043.x

[16] Hale, J.E., Dulek, R.E. \& Hale, D.P., Crisis response communication challenges: building theory from qualitative data. Journal of Business Communications, 42(2), pp. 112-134, 2005. http://dx.doi.org/10.1177/0021943605274751

[17] Jones, B.G. \& Chang, S.E., Economic aspects of urban vulnerability and disaster mitigation. In The Role of Engineering and Technology, Oxford: Elsevier Science Ltd, 1995. http://dx.doi.org/10.1016/b978-008041920-6/50030-0

[18] Dahlhamer, J.M., Artist, Small Business and the Whittier Narrows Earthquake: Loan Request Outcomes in the US Small Business Administration Disaster Loan Program for Businesses. [Art]. Department of Sociology, University of Delaware, 1992.

[19] Runyan, R.C., Small business in the face of crisis: Identifying barriers to recovery from a natural disaster. Journal of Contingencies and Crisis Management, 14, pp. 12-26, 2006.

[20] Corey,C.M. \& Deitch, E.A., Factors affecting business recovery immediately after Hurricane Katrina. Journal of Contingencies and Crisis Management, 19(3), pp. 169-181, 2011. http://dx.doi.org/10.1111/j.1468-5973.2011.00642.x

[21] Asgary, A., Anjum, M. \& Azimi, N., Disaster recovery and business continuity after the 2010 flood in Pakistan: Case of small businesses. International Journal of Disaster Risk Reduction, 2, pp. 46-56, 2012. http://dx.doi.org/10.1016/j.ijdrr.2012.08.001

[22] OSMEP, "SMEs Trend," 2005. [Online]. available at: http://www.sme.go.th.

[23] OSMEP, Situation and structural indicators of SMEs. In White Paper on Small and Medium Entreprises in Thailand in 2014, pp. 27-42, 2014.

[24] NSO, Statistical yearbook Thailand 2012. National Statistics Office. Ministry of Information and Communication Technology, Bangkok, 2012.

[25] Yamane, T., Statistics, An Introductory Analysis, 2nd ed., Harper and Row: New York 1967.

[26] Tran, P., Marincioni, F., Shaw, R., Sarti, M. \& Van An, L., Flood risk management in Central Viet Nam: challenges and potentials. Natural Hazards, 46, pp. 119-138, 2008. http://dx.doi.org/10.1007/s11069-007-9186-2

[27] Waiyahong, N., Information provision for thai small and medium sized enterprises (SMEs). Asia Pacific Journal of Library and Information Science, 2(2), pp. 117-124, 2012.

[28] Plate, E., Flood risk and flood management. Journal of Hydrology, 267, pp. 2-11, 2002. http://dx.doi.org/10.1016/S0022-1694(02)00135-X 
152 Flood Risk Management and Response

[29] Renn, O., Perception of risks. Toxicology Letters, 149, pp. 405-413, 2004. http://dx.doi.org/10.1016/j.toxlet.2003.12.051

[30] Hall, J.W., Dawson, R.J., Sayers, P.B., Rosu, C., Chatterton, J.B. \& Deakin, R., A methodology for national-scale flood risk assessment. Water Maritime Engineering, 156, pp. 235-247, 2003. http://dx.doi.org/10.1680/wame.2003.156.3.235

[31] Wilby, R.L., Beven, K.J. \& Reynard, N.S., Climate change and fluvial risk in the UK: more of the same? Hydrological Processes, 22, pp. 2511-2523, 2008. http://dx.doi.org/10.1002/hyp.6847

[32] Hattermann, F.F., Kundzewicz, Z.W., Huang, S., Vetter, T., Kron, W., Burghoff, O., et al., Flood risk in holistic perspective - observed changes in Germany. In: Changes in Flood Risk in Europe, Special Publication No. 10, ed. Z.W. Kundzewicz, IAHS Press, pp. 212-237, 2012. http://dx.doi.org/10.1201/b12348-14

[33] Kundzewicz, Z., Flood risk assessment-how certain are we? Climate-Impacts-2013. Org, pp. 1-10, 2013. 